\title{
Female hormones and the risk of colorectal neoplasm
}

\author{
Yunho Jung
}

Division of Gastroenterology, Department of Medicine, Soonchunhyang University College of Medicine, Cheonan, Korea

Received: August 4, 2019

Accepted: August 14, 2019

\section{Correspondence to \\ Yunho Jung, M.D.}

Division of Gastroenterology, Department of Medicine, Soonchunhyang University College of Medicine, 31 Suncheonhyang 6-gil, Dongnam-gu, Cheonan 31151, Korea

Tel: +82-41-570-3741

Fax: +82-41-574-5762

E-mail:yoonho7575@naver.com https://orcid.org/0000-00027760-0050

\section{See Article on Page 998-1007}

Cancer is a major cause of death worldwide. Gender affects the prevalence, prognosis, and mortality rate of various cancers $[1,2]$. In South Korea, in 2019, lung, stomach, and colorectal cancer (CRC) have been estimated to occur more frequently in men and breast, colorectal, and stomach cancer in women. Also, CRC is the third most common cause of cancer-related death in men and the second most common in women [2].

According to recent national statistics from the United States and the United Kingdom, the incidence of CRC is higher in men than in women $[1,3]$. In South Korea, the age-standardized incidence of CRC is higher in men (30.9 per 100,000) than in women (18.4 per 100,000) [2].

The sex difference in the incidence of cancer is likely to be related to biological, genetic/molecular, and behavioral factors. In terms of behavioral factors, men are more likely to consume large quantities of red and processed meat, drink alcohol, and smoke tobacco, and have a greater propensity to deposit visceral fat than women [3-7]. Also, female hormones (particularly estrogen), the levels of which differ by gender, exert a protective effect against CRC.

Regarding mechanisms, female hor- mones suppress the proliferation of CRC cells by binding to estrogen receptor $[8,9]$, which may suppress CRC by decreasing the levels of secondary bile acids and downregulating the expression level of insulin-like growth factor-1 $[10,11]$. To confirm the association between female hormones and colorectal neoplasm, it is necessary to investigate the degree of exposure to female hormones and the development of colorectal neoplasm considering the age at menarche, age at menopause, oral contraceptive, and combined estrogen-progestogen menopausal hormone therapy.

In a meta-analysis, women who had used oral contraceptives had a lower incidence of CRC than those who had not (relative risk [RR] 0.82; 95\% confidence interval [CI], 0.74 to 0.92 ) [12]. According to another meta-analysis, postmenopausal hormone therapy reduces the risk of colon cancer by $20 \%$ (RR, $0.80 ; 95 \% \mathrm{CI}, 0.74$ to 0.86 ) and that of rectal cancer by $19 \%$ (RR, 0.81; $95 \%$ CI, 0.72 to 0.92 ) [13].

According to a randomized, double-blind, placebo-controlled observational trial involving 10,739 postmenopausal women with prior hysterectomy, the use of estrogen alone did not affect the incidence of CRC or the rate of CRC-related mortality [14].

Age at menarche has been used as an indicator of lifetime exposure to en- 
dogenous female hormones; indeed, age at menarche ( $\geq 15$ vs. 11 to 12 years; hazard ratio (HR), 0.73; 95\% CI, 0.57 to $0.94 ; p=0.02$ ) was inversely associated with the risk of CRC but, according to a meta-analysis, menarcheal age was not [15]. Observational studies on the association of age at menopause with the risk of CRC have yielded inconclusive results $[16,17]$.

In recent prospective studies, the association between the serum estrogen level and the risk of CRC was inconsistent. Also, the levels of estrone $(p=0.001)$, free estradiol $(p \leq 0.0001)$, and total estradiol $(p=0.08)$ were inversely associated with the risk of CRC [18]. In contrast, the level of endogenous estradiol was positively associated with the risk of CRC (HR for high vs. low levels, 1.53; 95\% CI, 1.05 to 2.22$)$ [19].

In the latest issue of the Korean Journal of Internal Medicine, Kim et al. [20] report the relationship between reproductive factors (including age at menarche) and the risk of colorectal adenoma, based on the finding that colorectal adenoma is more common in men than in women $[21,22]$. According to their results, the incidence of any adenoma and of advanced adenoma increased with increasing age at menarche in univariate analyses; however, this positive association disappeared after adjusting for possible confounding factors. Thus, there was no significant relationship between age at menarche and adenoma or advanced adenoma in that study. Indeed, other reproductive factors-such as parity, use of female hormones, and menopausal status-were also not associated with the risk of adenoma in a multivariate analysis.

Recent studies have reported inconsistent results regarding the association between female hormones and the risk of colorectal adenoma. One study reported that parity and oral contraceptive use were not associated with adenoma risk, whereas increasing age at menopause and non-contraceptive hormone use were associated with a reduced risk of adenoma [23]. In contrast, a case-control study reported that women with menarche before 13 years of age had a lower risk of adenoma than those with late menarche, while parity, oral contraceptives, and non-contraceptive hormones were not associated with the risk of adenoma [24].

The above-mentioned studies do not facilitate the reaching of conclusions about the relationship between female hormones and CRC or colorectal adeno- ma. Such conclusions may require long-term follow-up and control of the various factors that affect colorectal neoplasms to reduce the level of bias. However, as most studies have found that the risk of CRC is higher in men than in women, further research on the mechanisms underlying the gender difference in the risk of CRC is warranted.

\section{Conflict of interest}

No potential conflict of interest relevant to this article was reported.

\section{Acknowledgments}

This work was supported by a Soonchunhyang University Research Fund.

\section{REFERENCES}

1. Siegel RL, Miller KD, Jemal A. Cancer statistics, 2016. CA Cancer J Clin 2016;66:7-30.

2. Jung KW, Won YJ, Kong HJ, Lee ES. Prediction of cancer incidence and mortality in Korea, 2019. Cancer Res Treat 2019;51:431-437.

3. White A, Ironmonger L, Steele RJC, Ormiston-Smith N, Crawford C, Seims A. A review of sex-related differences in colorectal cancer incidence, screening uptake, routes to diagnosis, cancer stage and survival in the UK. BMC Cancer 2018;18:906.

4. Kim HI, Lim H, Moon A. Sex differences in cancer: epidemiology, genetics and therapy. Biomol Ther (Seoul) 2018;26:335-342.

5. Chang LC, Wu MS, Tu CH, Lee YC, Shun CT, Chiu HM. Metabolic syndrome and smoking may justify earlier colorectal cancer screening in men. Gastrointest Endosc 2014;79:961-969.

6. Schutze M, Boeing H, Pischon T, et al. Alcohol attributable burden of incidence of cancer in eight European countries based on results from prospective cohort study. BMJ 2011;342:d1584.

7. Tchernof A, Despres JP. Pathophysiology of human visceral obesity: an update. Physiol Rev 2013;93:359-404.

8. Williams C, DiLeo A, Niv Y, Gustafsson JA. Estrogen receptor beta as target for colorectal cancer prevention. Cancer Lett 2016;372:48-56.

9. Di Leo A, Messa C, Cavallini A, Linsalata M. Estrogens 
and colorectal cancer. Curr Drug Targets Immune Endocr Metabol Disord 2001;1:1-12.

10. Huffman J, Hoffmann C, Taylor GT. Integrating insulin-like growth factor 1 and sex hormones into neuroprotection: implications for diabetes. World J Diabetes 2017;8:45-55.

11. McMichael AJ, Potter JD. Reproduction, endogenous and exogenous sex hormones, and colon cancer: a review and hypothesis. J Natl Cancer Inst 1980;65:1201-1207.

12. Fernandez E, La Vecchia C, Balducci A, Chatenoud L, Franceschi S, Negri E. Oral contraceptives and colorectal cancer risk: a meta-analysis. Br J Cancer 2001;84:722-727.

13. Grodstein F, Newcomb PA, Stampfer MJ. Postmenopausal hormone therapy and the risk of colorectal cancer: a review and meta-analysis. Am J Med 1999;106:574-582.

14. Lavasani S, Chlebowski RT, Prentice RL, et al. Estrogen and colorectal cancer incidence and mortality. Cancer 2015;121:3261-3271.

15. Li CY, Song B, Wang YY, et al. Age at menarche and risk of colorectal cancer: a meta-analysis. PLoS One 2013;8:e65645.

16. Buron Pust A, Alison R, Blanks R, et al. Heterogeneity of colorectal cancer risk by tumour characteristics: large prospective study of UK women. Int J Cancer 2017;140:10821090.

17. Tsilidis KK, Allen NE, Key TJ, et al. Oral contraceptives, reproductive history and risk of colorectal cancer in the European Prospective Investigation into Cancer and Nu- trition. Br J Cancer 2010;103:1755-1759.

18. Murphy N, Strickler HD, Stanczyk FZ, et al. A prospective evaluation of endogenous sex hormone levels and colorectal cancer risk in postmenopausal women. J Natl Cancer Inst 2015;107:djv210.

19. Gunter MJ, Hoover DR, Yu H, et al. Insulin, insulin-like growth factor-I, endogenous estradiol, and risk of colorectal cancer in postmenopausal women. Cancer Res 2008;68:329-337.

20. Kim NH, Park JH, Park DI, Sohn CI, Choi K, Jung YS. Age at menarche and risk of colorectal adenoma. Korean J Intern Med 2019;34:998-1007.

21. Park HW, Byeon JS, Yang SK, et al. Colorectal neoplasm in asymptomatic average-risk Koreans: the KASID prospective multicenter colonoscopy survey. Gut Liver 2009;3:35-40.

22. Choe JW, Chang HS, Yang SK, et al. Screening colonoscopy in asymptomatic average-risk Koreans: analysis in relation to age and sex. J Gastroenterol Hepatol 2007;22:10031008.

23. Peipins LA, Newman B, Sandler RS. Reproductive history, use of exogenous hormones, and risk of colorectal adenomas. Cancer Epidemiol Biomarkers Prev 1997;6:671-675.

24. Jacobson JS, Neugut AI, Garbowski GC, et al. Reproductive risk factors for colorectal adenomatous polyps (New York City, NY, United States). Cancer Causes Control 1995;6:513518. 